\title{
Design, synthesis and anti-HIV-1 RT evaluation of 2-(benzyl(4- chlorophenyl)amino)-1-(piperazin-1-yl)ethanone derivatives
}

Subhash Chander ${ }^{\mathrm{a}}$, Ping Wang ${ }^{\mathrm{b}}$, Penta Ashok ${ }^{\mathrm{a}}$, Liu-Meng Yang ${ }^{\mathrm{b}}$, Yong-Tang Zheng ${ }^{\mathrm{b}, *}$ and Murugesan Sankaranarayanan ${ }^{\mathrm{a}, *}$

\begin{abstract}
In this study, using molecular hybridization approach, fourteen novel 2(benzyl(4-chlorophenyl)amino)-1-(piperazin-1-yl)ethanone derivatives (7a-n) were designed as inhibitor of HIV-1 RT. The binding affinity of the designed compounds with HIV-1 RT as well as their drug-likeness behaviour was predicted using in-silico studies. All the designed compounds were synthesized, characterized and in-vitro evaluated for HIV-1 RT inhibitory activity, in which tested compounds displayed significant to weak potency against the selected target. Moreover, best active compounds of the series, $\mathbf{7 k}$ and $\mathbf{7 m}$ inhibited the activity of $\mathrm{RT}$ with $\mathrm{IC}_{50}$ values 14.18 and $12.26 \mu \mathrm{M}$ respectively. Structure Activity Relationship (SAR) studies were also performed in order to predict the influence of substitution pattern on the RT inhibitory potency. Anti-HIV-1 and cytotoxicity studies of best five RT inhibitor (7a, 7d, 7k, $7 \mathbf{l}$ and $\mathbf{7 m}$ ) revealed that, except compound $\mathbf{7 d}$ other compounds retained significant anti-HIV-1 potency with good safety index. Best scoring pose of compound $\mathbf{7 m}$ was analysed in order to predict its putative binding mode with wild HIV-1 RT.
\end{abstract}

Keywords: Enzymatic assay, Wild strain, Reverse transcriptase, Docking, Cytotoxicity 
AIDS is a serious health threat, which if untreated eventually leads to death, mostly due to opportunistic infections. ${ }^{1,2}$ UNAIDS 2015 report revealed that, around 36.7 million people were living with HIV globally, in the same year around 2.1 million new infections were reported and around 1.1 million people died from AIDS-related diseases. ${ }^{3}$ Highly Active Anti Retroviral Therapy (HAART) is the most widely adopted therapy against HIV/AIDS across the globe, which includes combination of three or more drugs having different mechanisms of action. ${ }^{4}$ Non-Nucleoside Reverse Transcriptase Inhibitors (NNRTIs) acting upon the reverse transcriptase enzyme of HIV-1 is an important class of antiretroviral drugs and widely used in HAART due to their less toxicity, high potency and high selectivity. ${ }^{5,6}$ Although, NNRTIs are structurally diverse in nature, but mechanistically all interact with the allosteric site of HIV-1 RT, also known as non-nucleoside inhibitory binding pocket (NNIBP) in a non-competitive manner, which results conformational changes in its catalytic domain, consequently leads to inhibition of its DNA polymerase activity. ${ }^{7,8}$ Although, HAART is effective for the reduction of viral load, but rapid development of drug resistance, in association with problems like difficulty in adherence to therapy and long-term side effects hampered the effectiveness of this therapy. ${ }^{9,10}$ To circumvent this problem, there is a continuous need of new anti-HIV drugs effective against the multiple strains of HIV with suitable pharmacokinetic profile.

Molecular hybridization is a rational approach to design novel ligands, involves the combination of two or more pharmacophoric subunits of known bioactive moieties and similar approach has been successfully utilized for the search of potent HIV-1 RT inhibitors. ${ }^{11-13}$ NNIBP is predominantly hydrophobic in nature and despite the structural diversity of NNRTIs, they possessed several common features, for example most of these constitute bulky aryl group connected to another hydrophobic or heteroaryl group via a hydrophilic linker. ${ }^{14}$ In this direction, Cushman and group reported a series of diaryl alkylidene based compounds as HIV-1 RT inhibitor, most potent compound of the series (A, Fig. 1) displayed sub-micromolar $\left(\mathrm{IC}_{50} 0.3 \mu \mathrm{M}\right)$ potency. ${ }^{15}$ Another series of compounds containing diarylmethane as bulky hydrophobic wings were also explored as HIV-1 RT inhibitors by Silvestri and group, compound B (Fig. 1) of this group inhibited RT activity with $\mathrm{IC}_{50}$ value $50 \mathrm{nM} .{ }^{16}$ In the last one decade, compounds containing diaryl ether has been well explored as potent NNRTIs, moreover clinically used block buster drug Etravirine also constitute the diaryl ether moiety. ${ }^{17-19}$ In similar study, Smith and group reported a series of 
compounds containing pyridone diaryl ether, in which one of the promising active compound (C, Fig. 1) exhibited $\mathrm{IC}_{50} 12 \mathrm{nM}$ against selected RT strain and $\mathrm{EC}_{50} 50 \mathrm{nM}$ against HIV-1. ${ }^{20}$

Although, compounds A-C are structurally diverse in nature, despite that these share some ubiquitous features, for example all three possess electron rich biaryl moiety (highlighted by the green color), which helps them to stabilize inside the hydrophobic NNIBP via hydrophobic or pi-pi stacking interactions and subsequently may be responsible for their potent RT inhibitory activity. So, inspired by these findings, model $\mathbf{E}$ was designed as prototype (Fig. 1) HIV-1 RT inhibitor, which constituted $N$-benzyl-p-chlorophenyl amine as electron rich hydrophobic entity (green color, E) attached with $N$-substituted ethanone piperazine, a bioisosters component (coral color highlight, Fig. 1) of compound D, which is already reported for RT inhibition. ${ }^{21,22}$ In the designed prototype $\mathbf{E}$, rationality for adding the $N$-benzyl ring was to provide extra flexibility, while $p$-chloro phenyl moiety was kept in order to increase the hydrophobic area of contact with receptor. Further, based upon the designed prototype $\mathbf{E}$, series of compounds (7a-n) was generated by making different substitution with phenyl or aryl group.

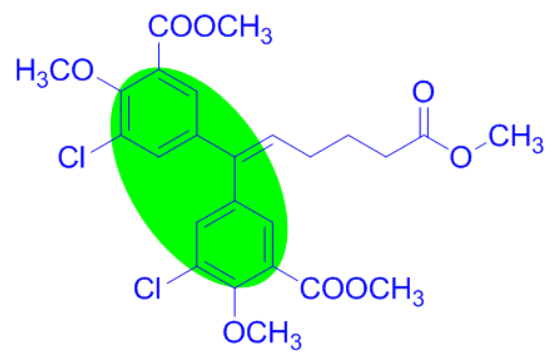

A

$\mathrm{IC}_{50}=0.3 \mu \mathrm{M}$

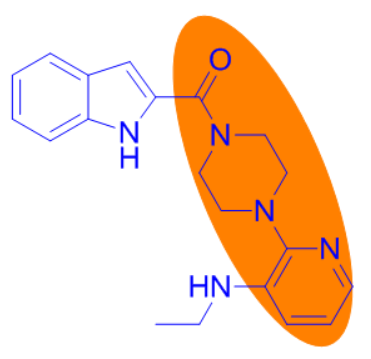

D

$$
\mathrm{IC}_{50}=4 \mu \mathrm{M}
$$

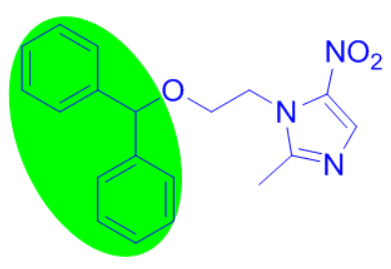

B

$\mathrm{IC}_{50}=50 \mathrm{nM}$

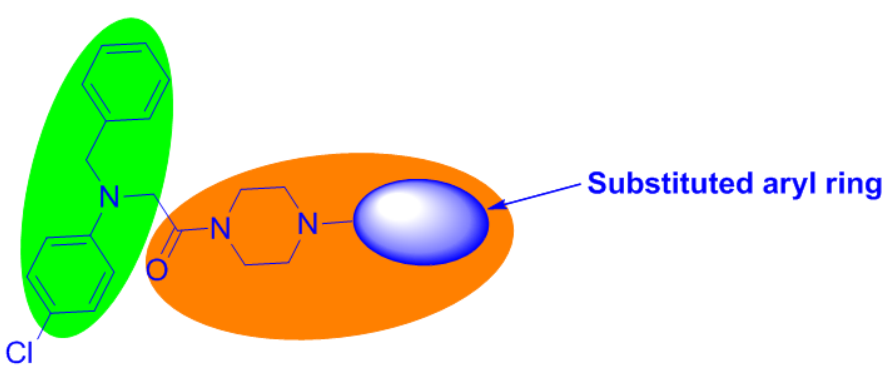

E

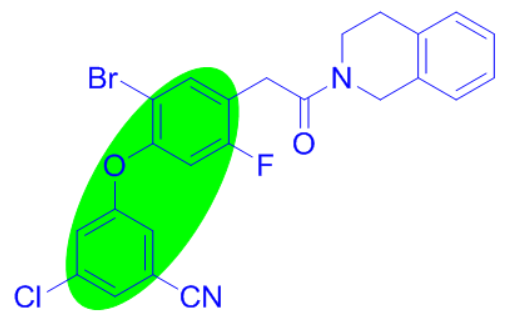

C

$\mathrm{IC}_{50}=12 \mathrm{nM}$

Figure 1. Literature reported HIV-1 RT inhibitors (A-D) and designed prototype model (E)

Pharmacokinetic properties play indispensible role in early stages of drug discovery and development, clinically approved drugs possess a favourable balance between 
pharmacokinetic properties and intrinsic potency. But, experimental determination of such properties for all novel molecules using in-vivo models is very costly, challenging and time consuming task. ${ }^{23,24}$ So, considering these factors, the drug-likeness behavior and pharmacokinetic parameters of the designed series was in-silico predicted using three different tools; Qik-prop module of Schrödinger, ${ }^{25}$ admetSAR ${ }^{26}$ and FAF-Drugs3. ${ }^{27}$

The optimum range of these parameters (followed by 95\% known drug molecules) is given in Table S1 (Supplementary information). The results of the predicted parameters (Table 1) for compounds (7a-n) revealed that, predicted values of Mol. Wt, HBD, HBA and $\log \mathrm{P}$ lied within the optimum range as described in Table S1. Although, $\operatorname{logS}$ value of compound $7 \mathbf{n}$ found to be lower than the prescribed optimum range ( -6.5 to 0.5 ), but it deviate by a small margin, which may not change its pharmacokinetic profile much significantly. So, considering this, compound $\mathbf{7 n}$ was retained for further studies. All compounds displayed good value of caco-2 cell permeability (PCaco), except compound 7k which exhibited moderate permeability. Values of other parameters like SASA, $\operatorname{logBB}$, Rot were also found within the optimum range. Further, none of the compounds exhibited predicted mutagenicity (predicted in qualitative terms). So, considering the predicted parameters, overall majority of the compounds possessed the drug-likeness behavior.

Table 1 In-silico predicted drug likeness and pharmacokinetic parameters of the titled compounds

\begin{tabular}{ccccccccccc}
\hline $\begin{array}{c}\text { Comp } \\
\text { Code }\end{array}$ & M Wt & SASA $^{\mathrm{a}}$ & HBD $^{\mathrm{b}}$ & HBA $^{\mathrm{c}}$ & $\log \mathrm{P}$ & $\operatorname{logS}$ & PCaco $^{\mathrm{d}}$ & $\operatorname{logBB}$ & Rot $^{\mathrm{f}}$ & Mut $^{\mathrm{g}}$ \\
\hline $\mathbf{7 a}$ & 419.18 & 726.04 & 0 & 4 & 5.57 & -6.23 & 5164.05 & 0.24 & 6 & None \\
$\mathbf{7 b}$ & 433.19 & 748.46 & 0 & 4 & 5.88 & -6.36 & 5606.61 & 0.28 & 6 & None \\
$\mathbf{7 c}$ & 433.19 & 758.24 & 0 & 4 & 5.90 & -6.44 & 5161.92 & 0.24 & 6 & None \\
$\mathbf{7 d}$ & 449.19 & 764.68 & 0 & 5 & 5.68 & -6.21 & 5417.31 & 0.20 & 7 & None \\
$\mathbf{7 e}$ & 449.19 & 763.21 & 0 & 5 & 5.63 & -6.18 & 5165.21 & 0.18 & 7 & None \\
$\mathbf{7 f}$ & 449.19 & 763.04 & 0 & 5 & 5.63 & -6.18 & 5197.91 & 0.18 & 7 & None \\
$\mathbf{7 g}$ & 437.17 & 732.21 & 0 & 4 & 5.74 & -6.24 & 5344.61 & 0.32 & 6 & None \\
$\mathbf{7 h}$ & 437.17 & 735.05 & 0 & 4 & 5.81 & -6.40 & 5165.42 & 0.36 & 6 & None \\
$\mathbf{7 i}$ & 453.14 & 750.13 & 0 & 4 & 6.07 & -6.27 & 5161.12 & 0.45 & 6 & None \\
$\mathbf{7 j}$ & 453.14 & 750.10 & 0 & 4 & 6.08 & -6.27 & 5165.16 & 0.42 & 6 & None \\
$\mathbf{7 k}$ & 464.16 & 781.60 & 0 & 7 & 4.87 & -6.19 & 429.54 & -0.99 & 7 & None \\
$7 \mathbf{7 l}$ & 433.19 & 778.21 & 0 & 4 & 6.34 & -6.37 & 5521.95 & 0.55 & 7 & None \\
\hline
\end{tabular}




\begin{tabular}{ccccccccccc}
\hline $\mathbf{7 m}$ & 487.10 & 765.82 & 0 & 4 & 5.02 & -5.10 & 1274.70 & 0.51 & 6 & None \\
$\mathbf{7 n}$ & 509.22 & 852.75 & 0 & 4 & 6.38 & $\mathbf{- 6 . 6 1}$ & 1355.44 & 0.47 & 8 & None \\
\hline
\end{tabular}

${ }^{\mathrm{a}}$ Solvent accessible surface area, ${ }^{\mathrm{b}}$ No. of hydrogen bond donors, ${ }^{\mathrm{c}}$ No. of hydrogen bond acceptors, ${ }^{\mathrm{d}}$ Predicted apparent Caco-2 cell permeability in $\mathrm{nm} / \mathrm{sec},{ }^{\mathrm{e}}$ Predicted brain/blood partition coefficient, ${ }^{\mathrm{f}}$ No. of rotatable bonds, ${ }^{\mathrm{g}}$ Mutagenicity

In order to predict the in-silico binding affinities of the designed compounds with HIV-1 RT, docking studies were performed using Glide ${ }^{28}$ module of Schrödinger in extra precision mode $^{29}$, taking efavirenz as reference ligand for comparison. HIV-1 RT enzyme used for the docking studies was wild type (no mutation at NNRTIs binding site), retrieved from Protein Data Bank (PDB ID: 3MEE) in complex with co-crystallized ligand rilpivirine (detailed protocol is given in the supplementary part). The value of RMSD obtained between superimposed (Fig. S1, supplementary information) re-docked pose of co-crystallized ligand and its experimental binding pose (as in X-ray) was found to be 0.64 , which suggested the reliability of docking protocol. In-silico binding affinities of the compounds are expressed in terms of Glide dock score ( $G$ score), which signify that more is the value of $G$ score (in negative term), greater will be the binding affinity of test compound with enzyme 3MEE. Dock score of test compounds (Table 2), revealed their moderate to excellent in-silico binding affinity (G score -8.97 to -12.41 ) with HIV-1 RT as compared to the reference drug efavirenz (-13.07).

Designed compounds (7a-n) were synthesized via four step synthetic route, details of the reaction conditions are summarized in scheme 1. First step involved reaction of $p$ chloroaniline (1) with benzaldehyde $\mathbf{2}$ using ethanol as solvent afforded imine $\mathbf{3}$ as intermediate, which on subsequent reduction with sodium borohydride using methanol as solvent gave $N$-benzyl-4-chloroaniline (4). In next step, intermediate 4 was treated with bromo acetic acid using acetonitrile as solvent and triethylamine as base under reflux conditions afforded compound 5. Further, coupling reaction of intermediate acid $\mathbf{5}$ with different substituted aryl piperazines (6a-n) in the presence of 1-hydroxybenzotriazole (HOBt) and 1-ethyl-3-(3-dimethylaminopropyl)carbodiimide hydrochloride (EDC.HCl) using triethylamine as base and dichloro methane (DCM) as solvent afforded final compounds (7an) in good to excellent yields. Details of synthetic procedure followed for the synthesis of titled compounds is provided in the supplementary information. 


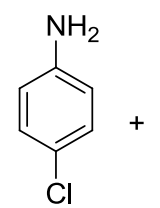

1<smiles>O=Cc1ccccc1</smiles>

2

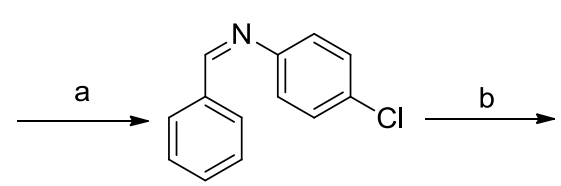

3

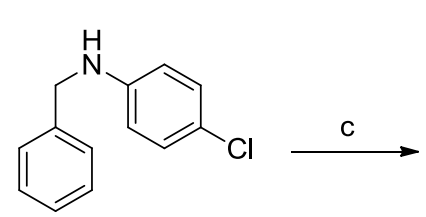

4<smiles>O=C(O)CN(Cc1ccccc1)c1ccc(Cl)cc1</smiles>

5
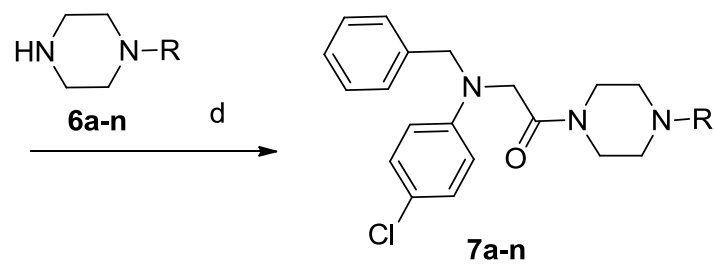

Scheme 1. Reagents and conditions: (a) EtOH, Caltalytic $\mathrm{AcOH}, 3 \mathrm{~h}$, reflux (b) $\mathrm{MeOH}, \mathrm{NaBH}_{4}, 0^{\circ} \mathrm{C}-$ rt, 2 h (c) $\mathrm{ACN}, \mathrm{BrCH}_{2} \mathrm{COOH}, \mathrm{Et}_{3} \mathrm{~N}$, reflux, 5 h (d) HOBT, EDC.HCl, Et ${ }_{3} \mathrm{~N}, \mathrm{DCM}$, rt, 6-8 h

All the synthesized compounds were characterized by spectral techniques like FT IR, ${ }^{1} \mathrm{H}$ NMR, ESI-MS and elemental analysis (spectral data is given in supplementary information). FTIR spectra of the titled compounds exhibited the expected absorption bands, for example, all compounds possessed amide linkage, a corresponding $\mathbf{C}=\mathbf{O}$ stretching peak (with strong intensity) appeared in IR spectra at $1645-1661 \mathrm{~cm}^{-1}$. The ${ }^{1} \mathrm{H}$ NMR spectra of the compounds showed characteristic singlet at $\delta \sim 4.65$ corresponding to two benzylic protons. Further, the two hydrogen of methylene group (at carbon connecting carbonyl group and nitrogen) appeared as singlet around $\delta \sim 4.19$. Position of eight piperazine protons in the proton spectra of series varied depending upon the nature of substitution, for example except compounds $7 \mathbf{l}$ and $\mathbf{7 m}$, these appeared at around $\delta \sim 3.85$ to 3.05 while in compounds $\mathbf{7 l}$ and $\mathbf{7 m}$, these appeared at around $\delta \sim 3.66$ to 3.43 . Proton counting and peak pattern of NMR signals corresponding to the other protons of compounds was observed in compliance with the proposed structure. The calculated and observed elemental values of $\mathrm{C} \mathrm{H} \mathrm{N}$ were found within the acceptable range. ESI-MS spectra of the synthesized compounds exhibited corresponding $\mathrm{M}+1$ peak.

HIV-1 RT inhibitory activity of the synthesized compounds (7a-n) was in-vitro evaluated using colorimetric ELISA kit in accordance with the kit protocol using efavirenz as reference positive control. ${ }^{30,31}$ The results of in-vitro assay revealed that, compounds $\mathbf{7 a}, \mathbf{7 b}$, 7d, 7k, $7 \mathbf{l}$ and 7m exhibited significant inhibition of HIV-1 RT with $\mathrm{IC}_{50} \leq 25 \mu \mathrm{M}$. Further, compounds 7c, 7e, $7 \mathbf{g}$ and $\mathbf{7 j}$ displayed moderate potency $\left(\mathrm{IC}_{50} 25>\right.$ to $\leq 40 \mu \mathrm{M}$ ), while rest of the compounds displayed weak to least RT inhibitory activity. Compound 7a having un- 
substituted phenyl ring showed significant potency against HIV-1 RT ( $\left.\mathrm{IC}_{50} 20.56 \mu \mathrm{M}\right)$. Substitution of phenyl ring with methyl group at ortho and para position (7b and 7c) slightly decreased their potency ( $\mathrm{IC}_{50} 23.47$ and $28.14 \mu \mathrm{M}$ respectively). Further, substitution with methoxy group slightly increased the potency at ortho position, while it decreased at meta and para position, so for methoxy substituted compounds (7d, 7e and 7f), potency against RT varied in the order ortho > meta > para. Compounds having fluoro substitution at ortho position (7g) exhibited moderate while at para position (7h) it showed weak potency. Furthermore, meta chloro substituted compound (7i) exhibited weak potency against RT, while chloro at para position (7j) showed moderate potency. Interestingly, para nitro substitution at phenyl ring (7k) found to be favourable for the HIV-1 RT inhibition $\left(\mathrm{IC}_{50}\right.$ $14.18 \mu \mathrm{M}$ ) and replacement of phenyl ring with benzyl (7l) slightly reduced the inhibitory potency $(21.51 \mu \mathrm{M})$. Further, upon di-substitution of phenyl ring with chloro $(\mathbf{7 m})$ resulted in enhancement of RT inhibitory activity, moreover compound $\mathbf{7 m}$ exhibited highest potency ( IC $_{50} 12.26 \mu \mathrm{M}$ ) against RT among the tested series. Replacement of phenyl ring with benzhydryl, a more bulky entity (7n) markedly decreases the potency against RT. So, overall SAR study revealed that, the RT inhibitory potency of the designed compounds changed significantly with change in nature as well as position of substitution. In general, compounds having un-substituted phenyl ring (7a), electron donating group like methoxy at ortho position (7d) and strong electron withdrawing nitro group at para position (7k) exhibited significant RT inhibitory potency. Moreover, replacement of phenyl with benzyl (7l) as well

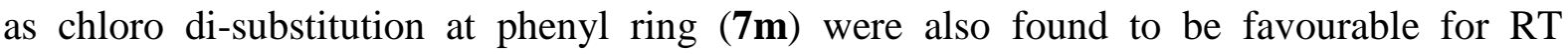
inhibitory activity.

Table 2 Results of in-vitro HIV-1 RT inhibition studies of the titled compounds

\begin{tabular}{clcc}
\hline Comp. Code & $\mathrm{R}$ & $\begin{array}{c}{ }^{\mathrm{a} R T} \text { inhibitory activity } \mathrm{IC}_{50} \\
(\mu \mathrm{M})^{\mathrm{a}}\end{array}$ & $\begin{array}{c}\text { Glide Score } \\
(\mathrm{G} \text { score })\end{array}$ \\
\hline $\mathbf{7 a}$ & $\mathrm{Ph}$ & $20.56 \pm 1.86$ & -11.67 \\
$\mathbf{7 b}$ & $2-\mathrm{Me}-\mathrm{Ph}$ & $23.47 \pm 1.34$ & -10.81 \\
$\mathbf{7 c}$ & $4-\mathrm{Me}-\mathrm{Ph}$ & $28.14 \pm 2.74$ & -10.24 \\
$\mathbf{7 d}$ & 2-MeO-Ph & $16.27 \pm 1.71$ & -11.08 \\
$\mathbf{7 e}$ & 3-MeO-Ph & $34.32 \pm 3.4$ & -10.16 \\
$\mathbf{7 f}$ & $4-\mathrm{MeO}-\mathrm{Ph}$ & $77.53 \pm 7.22$ & -11.15 \\
$\mathbf{7 g}$ & 2-F-Ph & $38.41 \pm 0.82$ & -9.58 \\
$\mathbf{7 h}$ & $4-\mathrm{F}-\mathrm{Ph}$ & $56.24 \pm 4.56$ & -8.97 \\
$\mathbf{7 i}$ & 3-Cl-Ph & $61.83 \pm 2.02$ & -11.76 \\
& & &
\end{tabular}




\begin{tabular}{clll}
\hline $\mathbf{7 j}$ & $4-\mathrm{Cl}-\mathrm{Ph}$ & $31.48 \pm 1.85$ & -11.48 \\
$\mathbf{7 k}$ & $4-\mathrm{NO}_{2}-\mathrm{Ph}$ & $14.18 \pm 1.21$ & -12.41 \\
$\mathbf{7 l}$ & $\mathrm{Benzyl}$ & $21.51 \pm 0.84$ & -10.26 \\
$\mathbf{7 m}$ & $2,3-\mathrm{DCl}-\mathrm{Ph}$ & $12.26 \pm 1.21$ & -12.07 \\
$\mathbf{7 n}$ & Benzhydryl & $>100$ & -10.28 \\
$\mathbf{E f a v i r e n z}$ & & $0.037 \pm 0.0056$ & -13.07 \\
\hline
\end{tabular}

${ }^{a}$ Average of at least duplicate independent experiments, \pm SD

Top five active HIV-1 RT inhibitors $\mathbf{7 a}, \mathbf{7 d}, \mathbf{7 k}, \mathbf{7 l}$ and $\mathbf{7 m}$ were evaluated for anti-HIV-1 activity (HIV-1 ${ }_{\text {IIIB }}$ strain) by cytopathic effect method, which measured the viability of HIV-1 infected cells. ${ }^{32}$ In this study, marketed drug zidovudine (AZT) was used as reference positive control. All five compounds were also evaluated for cytotoxicity against CD4 ${ }^{+}$ bearing T cells by MTT colorimetric assay. ${ }^{33}$ Details of experimental procedures followed for anti-HIV-1 assay and cytotoxicity are given in the supplementary part of this manuscript. The results of anti-HIV-1 activity and cytotoxicity studies (Table 3) revealed that, except compound $\mathbf{7 d}$, compounds $\mathbf{7 a}, \mathbf{7 k}, \mathbf{7 l}$ and $\mathbf{7 m}$ retained potency against HIV-1 with good safety index. Moreover, compound 7a exhibited most significant activity against HIV-1 among the tested compounds with $\mathrm{EC}_{50}$ value around $10.11 \mu \mathrm{M}$ and therapeutic index $>94.4$.

Table 3 Results of anti-HIV-1 activity and cytotoxicity of selected compounds

\begin{tabular}{cccc}
\hline Comp. Code & $\begin{array}{c}\text { Inhibition of syncytia } \\
\text { formation } \mathrm{EC}_{50}(\mu \mathrm{M})^{\mathrm{a}}\end{array}$ & $\begin{array}{c}\text { Cytotoxicity concentration } \\
\mathrm{CC}_{50}(\mu \mathrm{M})^{\mathrm{a}}\end{array}$ & $\begin{array}{c}\text { Therapeutic index } \\
(\mathrm{TI})\end{array}$ \\
\hline $\mathbf{7 a}$ & $10.11 \pm 0.72$ & $>954.24$ & $>94.4$ \\
$\mathbf{7 d}$ & $102.49 \pm 4.21$ & $228.32 \pm 19.45$ & 2.2 \\
$\mathbf{7 k}$ & $21.22 \pm 1.08$ & $>430.89$ & $>20.3$ \\
$\mathbf{7 1}$ & $13.64 \pm 0.78$ & $610.36 \pm 25.20$ & 44.7 \\
$\mathbf{7 m}$ & $11.52 \pm 0.68$ & $>410.59$ & $>35$ \\
Zidovudine & $0.013 \pm 0.004$ & $5858.85 \pm 440.12$ & 460505.88 \\
\hline
\end{tabular}

${ }^{a}$ Average of at least triplicate independent experiments, \pm SD

Comparative studies between the RT inhibition and anti-HIV-1 activity of top five compounds revealed that, compound like $\mathbf{7 m}$ displayed no significant difference in the RT inhibitory and anti-HIV-1 potency ( $\mathrm{IC}_{50} 12.26$ and $\mathrm{EC}_{50} 11.52$, respectively), so excellent corelation was observed between the both activity. Further compounds like 7k and $7 \mathbf{l}$ showed good/moderate co-relation between both activity with RSD (Relative Standard Deviation) around 28.12 and 31.66, respectively. Further, 7a possessed around two times more potent activity against HIV-1 as compared to RT and demonstrated comparatively weak co-relation. 
Compound 7d displayed significant potency against HIV-1 RT, but un-expectedly it showed around six times less potency against HIV-1 and thereby no co-relation between the both activities was observed.

Best docked pose of one significantly active compound (7m) was analysed in order to predict its putative binding mode inside the NNIBP of HIV-1 RT. Further, docked pose view of $\mathbf{7 m}$ (Fig. 2 and Fig. 3) revealed that, its chloro phenyl moiety exhibited prominent pi-pi stacking interaction with residues Tyr-188; it also interacted with Phe-227 and Trp-229 via hydrophobic interaction, while second aromatic wing (benzyl) exhibited similar interactions with Val-106 and Trp-318. Further, central axis of compound $\mathbf{7 m}$ consisting of aceto phenyl piperazine moiety showed hydrophobic interactions with Tyr-181 and Val-179. So, presence of prominent pi-pi stacking and hydrophobic interactions may be responsible for strong binding of $\mathbf{7 m}$ inside the NNIBP and subsequently for significant HIV-1 RT inhibitory activity.

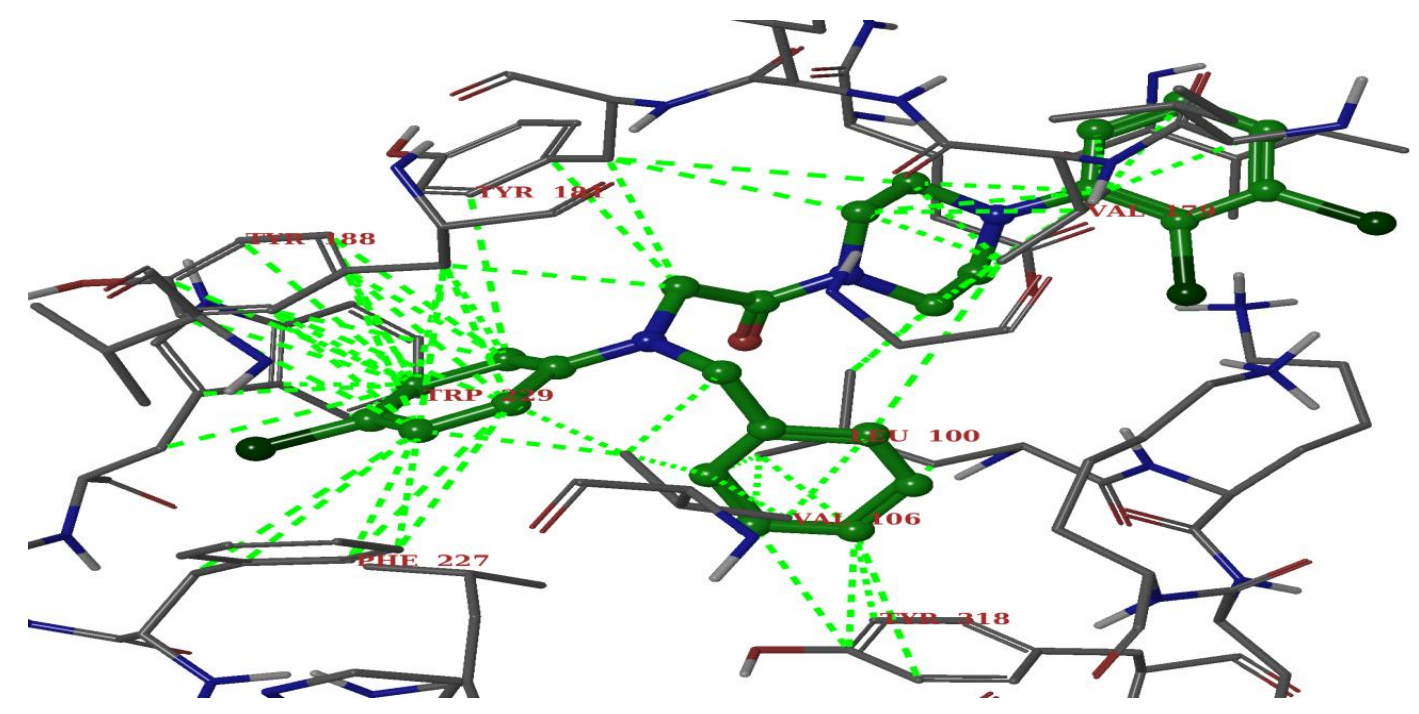

Figure 2. Three dimensional docked view of compound $\mathbf{7 m}$ inside the NNIBP of 3MEE showing hydrophobic interaction represented by green dotted lines 


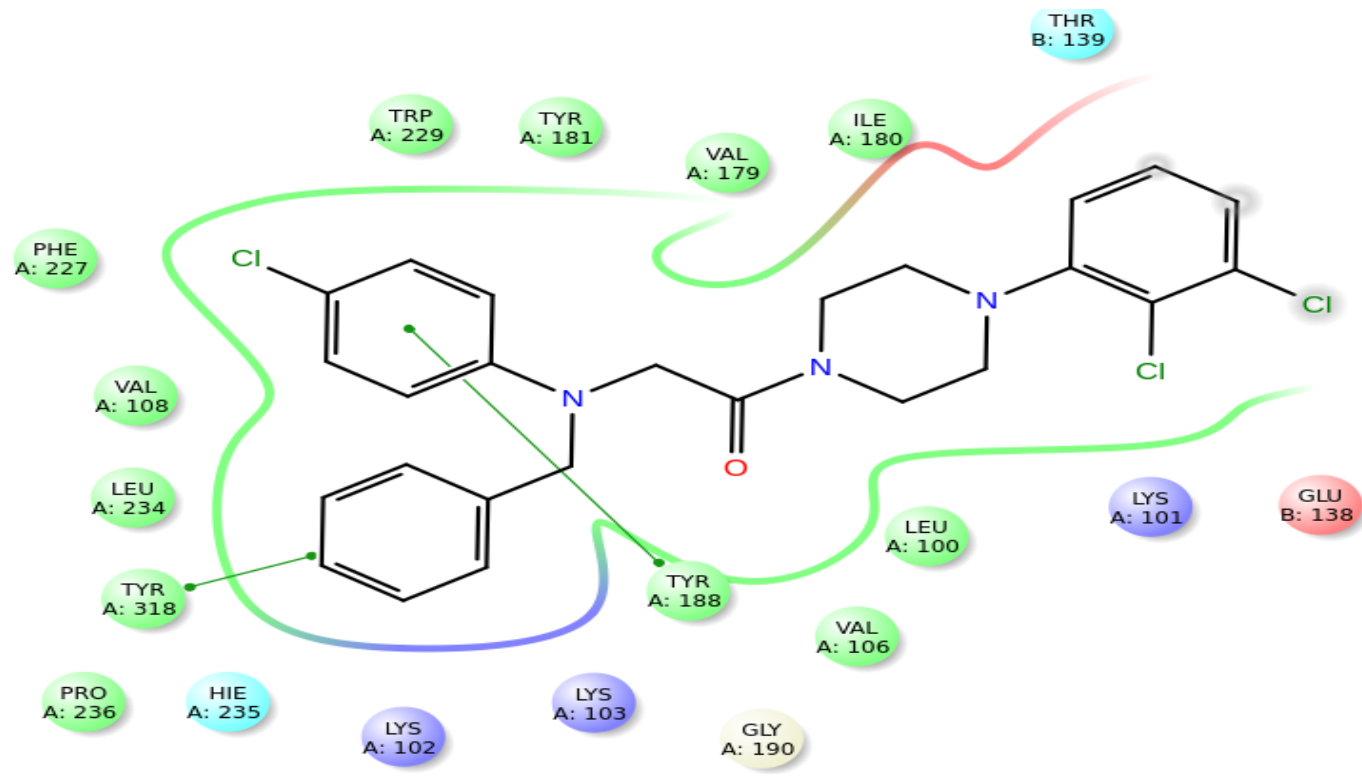

Figure 3. Docked pose of compound $7 \mathbf{m}$ inside the NNIBP of 3MEE showing two-dimensional interactive diagram

In summary, fourteen novel 2-(benzyl(4-chlorophenyl)amino)-1-(piperazin-1yl)ethanone derivatives were designed, synthesized and evaluated for HIV-1 RT inhibitory activity, in which compounds $\mathbf{7 a}, \mathbf{7 b}, \mathbf{7 d}, \mathbf{7 k}, \mathbf{7 l}$ and $\mathbf{7 m}$ exhibited significant inhibition of HIV-1 RT ( IC $_{50} \leq 25 \mu \mathrm{M}$ ). Further, among the top five RT inhibitors evaluated for anti-HIV-1 activity and cytotoxicity studies, except compound 7d, others compounds (7a, 7k, 7l and 7m) retained significant anti-HIV-1 potency with good safety index. Docking studies of compound 7m against wild HIV-1 RT revealed its prominent pi-pi stacking and hydrophobic interactions within NNIBP of selected RT strain, which may be responsible for its strong binding affinity with receptor and subsequently for significant HIV-1 RT inhibitory activity. So, overall studies can be helpful in the direction of further lead optimization or designing of novel potent anti-HIV agents.

\section{Acknowledgments}

Authors gratefully acknowledge BITS-Pilani for providing the necessary facilities to do this work. This work was carried out under a grant from Science and Engineering Research Board of Department of Science and Technology, New Delhi. (Ref. No: SR/FT/LS-58/2011), the National Science Foundation of China (81102483) and the STS Program of CAS (KFJ-EW-STS-026). 


\section{Supplementary data}

Supplementary data associated with this article can be found, in the online version, at $\operatorname{xxxxxxxxxxx}$

\section{References and notes}

[1] https://www.aids.gov/hiv-aids-basics/hiv-aids-101/what-is-hiv-aids/ (accessed on $7^{\text {th }}$ July 2016).

[2] Faria, N. R.; Rambaut, A.; Suchard, M. A.; Baele, G.; Bedford, T.; Ward, M. J.; Tatem, A. J.; Sousa, J. D.; Arinaminpathy, N.; Pepin, J.; Posada, D.; Peeters, M.; Pybus, O. G.; Lemey, P. Science (New York, N.Y.) 2014, 346, 56.

[3] http://www.unaids.org/en/resources/fact-sheet (accessed on $9^{\text {th }}$ July 2016.

[4] Granich, R.; Crowley, S.; Vitoria, M.; Smyth, C.; Kahn, J. G.; Bennett, R.; Lo, Y. R.; Souteyrand,Y.; Williams, B. Curr. Opin. HIV AIDS. 2010, 5, 298.

[5] de Béthune, M. P. Antiviral Res. 2010, 85, 75.

[6] Meng, Q.; Chen, X.; Kang, D.; Huang, B.; Li, W.; Zhan, P.; Daelemans, D.; De Clercq, E.; Pannecouque, C.; Liu, X. Eur. J. Med. Chem. 2016, 115, 53.

[7] Sluis-Cremer, N.; Tachedjian, G. Virus Res. 2008, 134, 147.

[8] Chander, S.; Penta, A.; Murugesan, S. Med. Chem. Res. 2015, 24, 1869.

[9] Chander, S.; Ashok, P.; Singh, A.; Murugesan, S. Chem. Cent. J. 2015, 9, 33.

[10] Bartlett, J. A.; Shao, J. F.; Lancet Infect. Dis. 2009, 9, 637.

[11] Chander, S.; Ashok, P.; Cappoen, D.; Cos, P.; Murugesan, S. Chem. Biol. Drug Des. 2016, (accepted, doi: 10.1111/cbdd.12788)

[12] Chakka, S. K.; Kalamuddin, M.; Sundararaman, S.; Wei, L.; Mundra, S.; Mahesh, R.; Malhotra, P.; Mohmmed, A.; Kotra, L. P. Bioorg. Med. Chem. 2015, 23, 2221.

[13] Chander, S.; Wang, P.; Ashok, P.; Yang, L. M.; Zheng, Y. T.; Murugesan, S. Bioorg. Chem. 2016, 67, 75.

[14] Li, D.; Zhan, P.; De Clercq, E.; Liu, X. J. Med. Chem. 2012, 55, 3595.

[15] Cushman, M.; Casimiro-Garcia, A.; Hejchman, E.; Ruell, J. A.; Huang, M.; Schaeffer, C.A.; Williamson, K.; Rice, W.G.; Buckheit, R.W. J. Med. Chem. 1998, 41, 2076.

[16] Silvestri, R.; Artico, M.; Massa, S.; Marceddu, T.; De Montis, F.; La Colla, P. Bioorg. Med. Chem. Lett. 2000, 10, 253. 
[17] Sweeney, Z. K.; Harris, S. F.; Arora, N.; Javanbakht, H.; Li, Y.; Fretland, J.; Davidson, J. P.; Billedeau, J. R. J. Med. Chem. 2008, 51,7449.

[18] Sweeney, Z. K.; Kennedy-Smith, J. J.; Wu, J.; Arora, N.; Billedeau, J. R.; Davidson, J. P.; Fretland, ChemMedChem. 2009, 4, 88.

[19] https://www.drugs.com/ppa/etravirine.html, (accessed on $10^{\text {th }}$ June 2016)

[20] Kennedy-Smith, J. J.; Arora, N.; Billedeau, J. R.; Fretland, J.; Hang, J. Q.; Heilek, G. M.; Harris, S. F. Med. Chem. Comm. 2010, 1,79.

[21] Romero, D. L.; Morge, R. A.; Genin, M. J.; Biles, C.; Busso, M.; Resnick, L.; Althaus, I.W.; Reusser, F. J. Med. Chem. 1993, 36,1505.

[22] Xu, H. Mini. Rev. Med. Chem. 2010, 10, 62.

[23] Van de Waterbeemd, H.; Gifford, E. Nat. Rev. Drug Discov. 2003, 2, 192.

[24] Moroy, G.; Martiny, V. Y.; Vayer, P.; Villoutreix, B. O.; Miteva, M. A. Drug Discov. Today 2012, 17, 44.

[25] Qik-prop. New York, Schrödinger, LLC, 2013, Version 3.7.

[26] Cheng, F.; Li, W.; Zhou, Y.; Shen, J.; Wu, Z.; Liu, G. J. Chem. Inf. Model 2012, 52, 3099.

[27] Lagorce, D.; Sperandio, O.; Baell, J. B.; Miteva, M. A.; Villoutreix, B. O. Nucl. Acids. Res. 2015, 43, W200.

[28] Glide, Schrödinger, LLC, New York, 2013, version 5.9.

[29] Friesner, R. A.; Murphy, R. B.; Repasky, M. P.; Frye, L. L.; Greenwood, J. R.; Halgren, T. A.; Sanschagrin, P. C.; Mainz, D. T. J. Med. Chem. 2006, 49, 6177.

[30] Eberle, J.; Knopf, C. W. Methods Enzymol. 1996, $275,257$.

[31] Chander, S.; Ashok, P.; Zheng, Y. T.; Wang, P.; Raja, K. S.; Taneja, A.; Murugesan, S. Bioorg. Chem. 2016, 64, 66.

[32] Wang, R. R.; Gu, Q.; Wang, Y. H.; Zhang, X. M.; Yang, L. M.; Zhou, J.; Chen, J. J.; Zheng, Y. T. J. Ethnopharmacol. 2008, 117, 249.

[33] Zheng, Y. T.; Ben, K. L.; Jin, S. W. Acta Pharmacol Sin. 1999, 20, 243. 


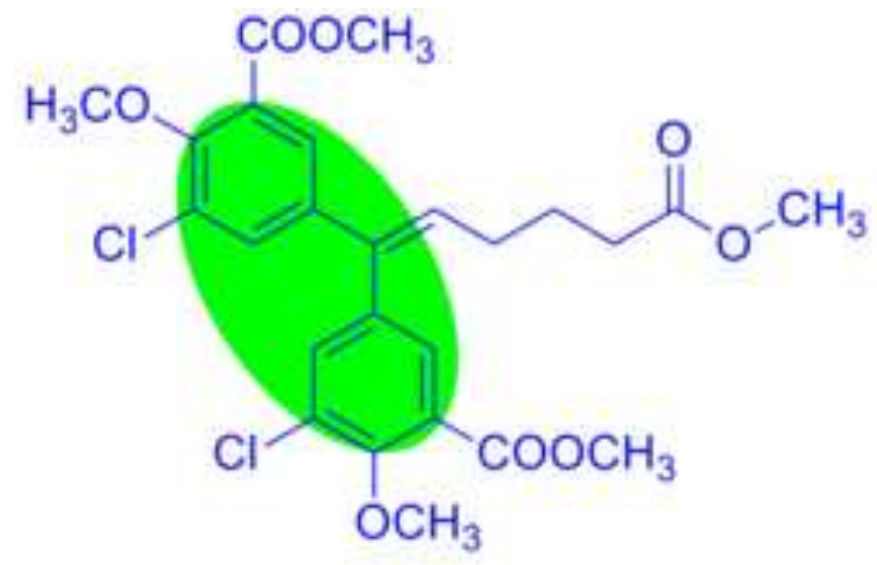

A

$\mathrm{IC}_{50}=0.3 \mu \mathrm{M}$

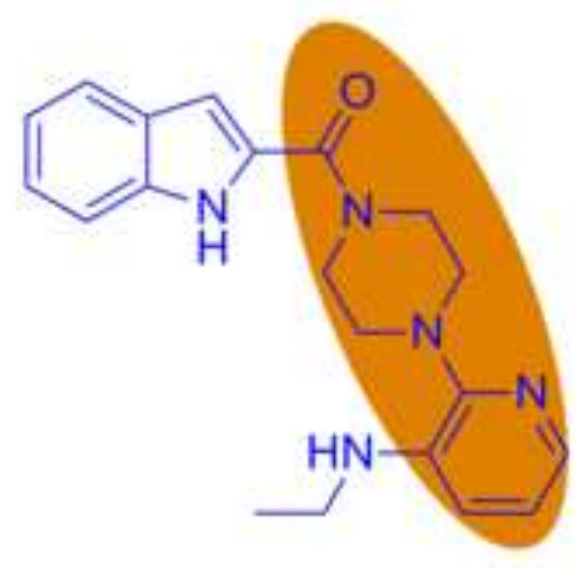

D

$\mathrm{IC}_{50}=4 \mu \mathrm{M}$

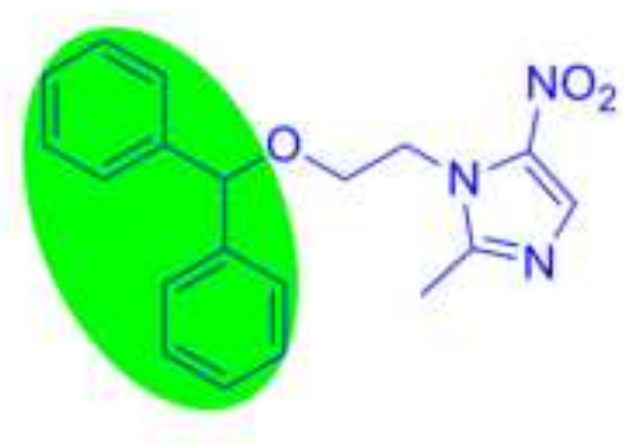

B

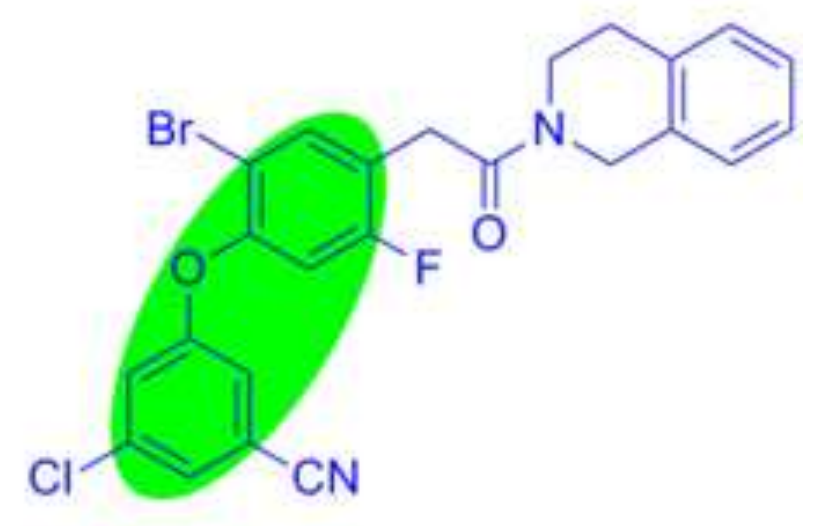

C
$\mathrm{IC}_{50}=50 \mathrm{nM}$

$I_{50}=12 \mathrm{nM}$

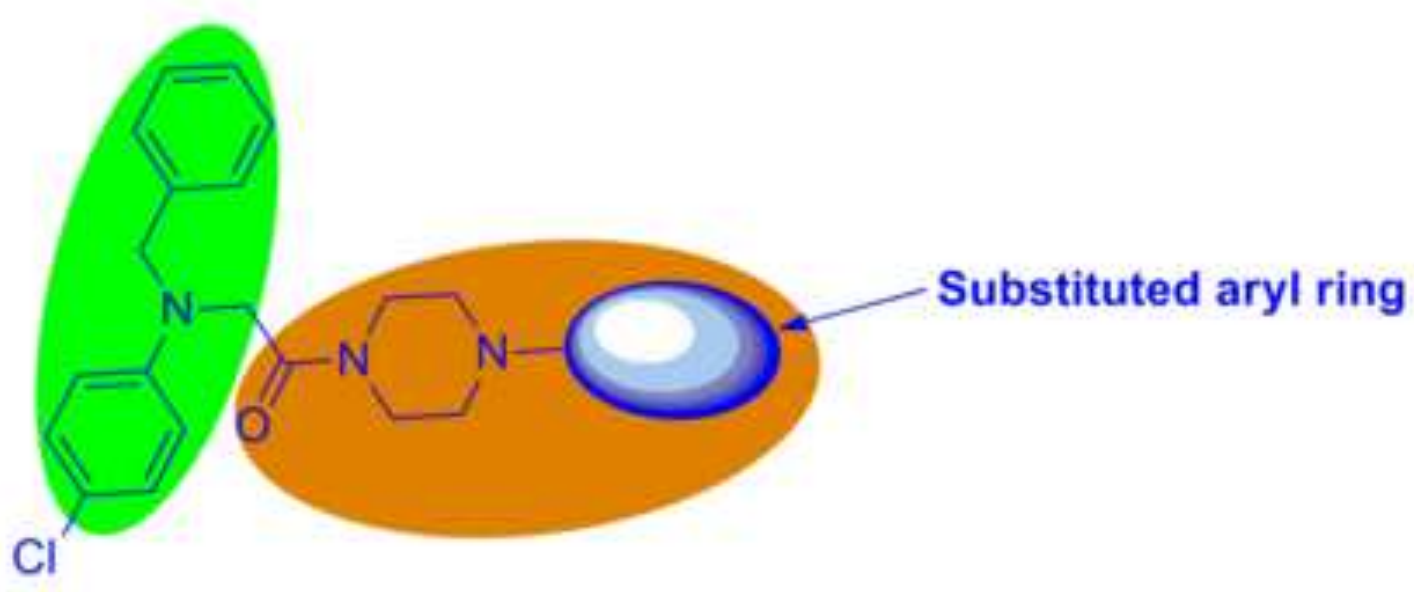

E

Designed prototype model 